\title{
Phoenix I Energy Extraction Experiment
}

James M. Hoffman, Edward L. Patterson, Gary C. Tisone, James B. Moreno

Prepared by Sandia Laboratories, Albuquerque, New Mexico 87185 and Livermore, California 94550 for the United States Department of Energy under Contract DE-ACO4-76DPO0789

Printed July 1980 


\section{DISCLAIMER}

This report was prepared as an account of work sponsored by an agency of the United States Government. Neither the United States Government nor any agency Thereof, nor any of their employees, makes any warranty, express or implied, or assumes any legal liability or responsibility for the accuracy, completeness, or usefulness of any information, apparatus, product, or process disclosed, or represents that its use would not infringe privately owned rights. Reference herein to any specific commercial product, process, or service by trade name, trademark, manufacturer, or otherwise does not necessarily constitute or imply its endorsement, recommendation, or favoring by the United States Government or any agency thereof. The views and opinions of authors expressed herein do not necessarily state or reflect those of the United States Government or any agency thereof. 


\section{DISCLAIMER}

Portions of this document may be illegible in electronic image products. Images are produced from the best available original document. 
Issued by Sandia Laboratories, operated for the United States Department of Energy by Sandia Corporation.

\section{NOTICE}

This report was prepared as an account of work sponsored by the United States Government. Neither the United States nor the Department of Energy, nor any of their employees, nor any of their contractors, subcontractors, or their employees, makes any warranty, express or implied, or assumes any legal liability or responsibility for the accuracy, completeness or usefulness of any information, apparatus, product or process disclosed, or represents that its use would not infringe privately owned rights. 


\section{PAGES 1 to 2 WERE INTENTIONALLY LEFT BLANK}


This book was fievaltet as an account ot work sponsored by an agency of the United States Government. Neither the United States Government nor any agency thereof, nor any of their employees, makes any completeness, or usetuthess. Of assumes any legal liability or responsibility for the eccuracy, represents that its use would not intringo privately opparatus, product. or process disclosed, or commercial product, process, or sevvice by trode name, tredemark, manufacturer, or to any specitic not necesserily constitute or imply its encorsernent, resemmend manutacturer. or otherwise, does

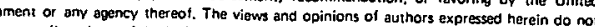

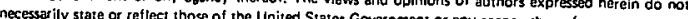

\author{
James M. Hoffman, Edward L. Patterson, Gary C. Tisone, \\ and James B. Moreno \\ Sandla National Laboratorles \\ Albuquerque, New Mexico 87185
}

\title{
ABSTRACT
}

Energy extraction experiments are reported for the Phoenix I amplifier driven by a discharge-initiated oscillator-preamplifier system operating on mixtures of either $\mathrm{SF}_{6}-\mathrm{HI}$ or $\mathrm{SF}_{6}-\mathrm{C}_{2} \mathrm{H}_{6}$ and an electron-beam-initiated Intermediate amplifier $(\lambda-3)$ fueled with $\mathrm{H}_{2}$ and $\mathrm{F}_{2}$ mixtures. Input intensities in this experiment were as large as those provided in the previous energy-extraction experiments where the oscillator operated with mixtures of $\mathrm{H}_{2}$ and $\mathrm{F}_{2}$. When the oscillator-preamplifier system operated with mixtures of $\mathrm{SF}_{6}-\mathrm{HI}$ the input spectrum to the Phoenix I amplifier contained $\sim 28$ P-branch vibrational-rotational ines which were almost identical to the input spectrum from the $\mathrm{H}_{2}-\mathrm{F}_{2}$ fueled oscillator. In this case the energy extraction measurements were essentially the same as the results obtained with the spectrum produced using $\mathrm{H}_{2}$ and $\mathrm{F}_{2}$ mixtures. For an input intensity of $10^{7} \mathrm{~W} / \mathrm{cm}^{2}, 170 \mathrm{~J}$ were extracted from the amplifier. Energy-extraction measurements made with the oscillator-preamplifier operating with $\mathrm{SF}_{6}-\mathrm{C}_{2} \mathrm{H}_{6}$ mixtures with 20 P-branch lines gave values of extracted energy which were only $16 \%$ lower than the values obtained with similar intensities using the $\mathrm{SF}_{6}-\mathrm{HI}$ spectrum. With the $\mathrm{SF}_{6}-\mathrm{C}_{2} \mathrm{H}_{6}$ spectrum, extraction was only obtained from the first three excited vibrational levels. This result indicates that most of the energy in the amplifier could be extracted on the first three exclted vibrational levels. It is shown that the extraction results can be fit with a simple two level model. Calculations using this simple model as well as a comprehensive HF code Indicate that paraeitic osclilations must be lncluded when modeling the energy extraction characteristics of the Phoenix I amplifier.

Amplified spontaneous emission was reduced by a factor of 2 to 3 when the input intensity was increased from 0 to $1 \times 10^{6} \mathrm{~W} / \mathrm{cm}^{2}$. Further increases in the input intensity did not further reduce the amplified spontaneous emission.

The radius of curvature of the beam was estimated using a lateral shearing interferometer. It was found that the Phoenix I amplifier altered the radius of curvature.

Printed in the United States of America

Available from

National Technical Information Service

U. S. Department of Commerce

5285 Port Royal Road

Springfield, Virginia 22161

Price: Printed Copy $\$ 4.00$ Microfiche $\$ 3.00$ 


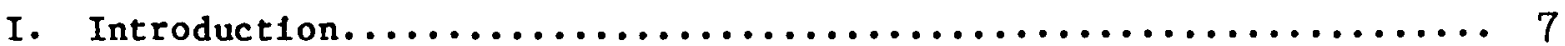

II. Experimental Detalls........................... 9

III. $\operatorname{Results} \ldots \ldots \ldots \ldots \ldots \ldots \ldots \ldots \ldots \ldots \ldots \ldots \ldots \ldots \ldots \ldots \ldots \ldots \ldots \ldots \ldots$

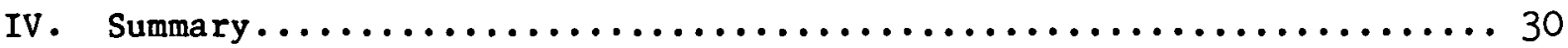

Fig. 1. Schematic representation of saturated amplifier experiment.... 10

Fig. 2. Time correlation for the $\lambda-3$ intermediate amplifier between electron-beam current, total output and various P-branch transitions for the $\lambda-3$ system configured as an oscillator.... II

Fig. 3. Temporal behavior of the strongest vibrational-rotational lines from the oscillator-preamplifier. The time of the maximum perlods over which the intensity levels are greater than $10 \%$ and $50 \%$ are indicated. The shaded area indicates the time chosen for the oscillator signal and the start of positive gain in the intermediate amplifier to overlap....... 13

Fig. 4. Relative intensity profile of Input beam Into Phoenix I amplifier. The vertical profile and horizontal profile are indicated. The horizontal profile has been shifted so that both profiles can be distingulshed. One marked division of the abscissa is equal to one centimeter................. 15

Fig. 5. Time correlated signals from the saturated amplifier experiment. The input and output energies are indicated...... 16

Fig. 6. Energy extraction from Phoenix I as a function of input intensity. The error in measurement of the extracted energy is estimated to be $\pm 10 \%$ and the error in determining the input intensity is estimated to be $\pm 20 \%$. The total available extracted energy from the amplifier is indicated to be $180 \mathrm{~J}$. The solid curve is the -result of a simple parasitic model with the following parameters: $g_{g} L=23, g_{t} L=5.5$, and $\mathrm{R}_{\text {eff }}=0.004$. The curve marked "No Parasitics" indicates the simple model predictions for energy extraction when the reflectión paramelei ls sel equal lo zeru............. 18 
Fig. 7. Energy gain of Phoenix I as a function of Input energy...... 20

Fig. 8. Schematic representation of steady-state parasitic model. $R_{f}$ and $R_{0}$ are the reflectivity of the input and output whindow, respectively. $I_{p}^{+}$is the input intensity into the amplifier and $I_{0}^{+}$is the amplifier output intensity. $I_{0}^{-}$ is the intensity reflected along the amplifier optical axis from the output window. $I_{i}$ is the amplified backward intensity on the input window and $I_{i}^{+}$is the total intensity in the forward direction......................... 23

Fig. 9. Extracted energy as a function of input intensity for Phoenix I. The discrete points are measured values; the dashed and solid curves are calculations using the comprehensive code. The predictions are based on an approximate accounting for parasitic oscillations......... 26

Fig. 10. Phoenix I shear plate interferogram................. 29

TABLE CAPTIONS

Table I. Sma11-Signal-Gain-Length Product Obtained from Phoenix I Data Using a Two-Level Steàdy-scare Amplifler Mudel........ el

Table II. Sma11-Signal-Gain-Length Product obtained from Present Phoenix I Extraction llata Joling a Two-Level steady-State Allplifier Model............................. 21

Table III. Spectral Comparison with Varlous Gas Mixtures.......... 28 


\section{Introduction}

In previous extraction experiments ${ }^{1}$ using a master-oscillator, power-amplifier (MOPA) arrangement, it was shown that it was possible to extract greater than $90 \%$ of the avallable energy from the Phoen1x I amplifier. The input intensity required to obtain this extraction efficiency was $2 \times 10^{7} \mathrm{~W} / \mathrm{cm}^{2}$. In those experiments both the oscillator and the amplifier were operated with simllar gas mixtures of $\mathrm{H}_{2}$ and $\mathrm{F}_{2}$, which assured a good spectral match between the osclllator and amplifier.

In another experiment, ${ }^{2}$ energy extraction and beam-quality measurements for the Phoenix I amplifier were reported for which the electron-beam-initiated oscillator was replaced by an oscillator and preamplifier chain utilizing ": fast electrical discharges in $\mathrm{SF}_{6}$-HI mixtures. This osc11lator-preamplifier system produced a spectrum that did not contaln the same vibrational-rotational IInes as the $\mathrm{H}_{2}-\mathrm{F}_{2}$. spectrum. For input intensities of $7.4 \times 10^{4}$ and $1.5 \times 10^{5} \mathrm{~W} / \mathrm{cm}^{2}$, the output energy from Phoentx I was $33 \mathrm{~J}$ and $46 \mathrm{~J}$, respectively. The corresponding extraction efficiencles ( $19 \%$ and $26 \%$ ) were in good agreement with the results obtalned using the $\mathrm{H}_{2}-\mathrm{F}_{2}$-fueled oscillator at the same input intensities. In this earlier experiment ${ }^{2}$ the beam quality was inferred from the encircled energy distribution determined by measuring the energy transmitted through various size pinholes located at the focus of an off-axis parabolic mirror. The enclrcled-energy measurements demonstrated that the spot size for which $84 \%$ of the incident energy was transmitted was $154 \mathrm{\mu m}$ corresponding to 2.7 times the diffraction-1imited diameter for the same fraction of encircled energy. The corresponding diameter for the unamplified beam was $100 \mu \mathrm{m}$ which $1 \mathrm{~s}$ about 1.8 times the diffraction-11mited diameter. The cource of the apparent increase in gpot size in the amplified beam is not known at this time. The wavefront curvature was determined by 
use of lateral-shearing interferometry. ${ }^{3}$ Measurement of the rotation of the fringes with respect to the reference wire on the lateral shearing interferometer indicated that both beams (input and amplified) had a radius of curvature of $350 \pm 50 \mathrm{~m}$. Th1s corresponds to a full-angle divergence of $200 \pm 30 \mu \mathrm{rad}$. These results demonstrated that at these input intensitles the amplifier did not change the radius of curvature of the wavefront.

The results of these previous experiments can be summarized as follows:

1. Ënergy can be efficlently extracted trom the phoenix I amplifier wlth an input intensity of about $2 \times 10^{7} \mathrm{~W} / \mathrm{cm}^{2}$ from an oscillator operating on mixtures of $\mathrm{H}_{2}$ and $\mathrm{F}_{2}$.

2. The extraction efficiency at low input intensities $\left(1 \cdot x 10^{5} \mathrm{~W} / \mathrm{cm}^{2}\right)$ utilizing mixtures of $\mathrm{SF}_{6}-\mathrm{HI}$ in a discharge-initiated system is just as good as with electron-beam-initiated $\mathrm{H}_{2}$ and $\mathrm{F}_{2}$ mixtures.

3. The encircled-energy measurements indicate that amplification of the beam Increased the focal spot size from $100 \mu \mathrm{m}$ to $154 \mu \mathrm{m}$.

Results 2 and 3 were obtalned at relatively low input intensities, and the effect of utilizing an $\mathrm{SF}_{6}-\mathrm{HI}$ or $\mathrm{SF}_{6}-\mathrm{C}_{2} \mathrm{H}_{6}$ input spectrum at higher intensities was unknown. Therefore, a third extraction experiment on the Phoentx I amplifier was performed. The objective of this experiment was to determine the efficlency of energy extraction from the Phoenix I amplifier using the discharge-inftiated oscillator-preamplifier system operating on mixtures of $\mathrm{SF}_{6}-\mathrm{HI}$ or $\mathrm{SF}_{6}-\mathrm{C}_{2} \mathrm{H}_{6}$, and an electron-beam-initiated intermediate amplifier fueled with $\mathrm{H}_{2}$ and $\mathrm{F}_{2}$ mixtures, to generate a saturating input for the Phoenix I amplifier. This arrangement was designed to deliver sufficient input intensity to saturate Phoentx I but in a different spectrum than was provided by the $\mathrm{H}_{2}-\mathrm{F}_{2}$-fueled oscillator. 


\section{Experimental Detalls}

The Phoenfx I oscillator-preamplifler-amplifier chain used in this experiment is shown schematically in Fig. 1. The electrical-discharge-initiated oscillator and preamplifier system is similar to that described by Arnold and Wenzel..$^{4}$ The $\lambda-3$ intermediate amplifier ${ }^{5}$ and Phoenix I amplifier ${ }^{6}$ have described previously. The osclilator and preamplifiers produced a near-diffraction-limited beam with an energy output of about $1 \mathrm{~J}$ with a pulse width of $120 \mathrm{nsec}$. In these extraction experiments the oscillator-preamplifier system was operated with gas mixtures of $\mathrm{SF}_{6}$ and $\mathrm{HI}$ or $\mathrm{SF}_{6}$ and $\mathrm{C}_{2} \mathrm{H}_{6}$. The $\mathrm{SF}_{6}$ and $\dot{\mathrm{H} I}$ mixture was chosen because the reaction $F+H I \rightarrow H F+I$ has been shown to result in formation of $\mathrm{HF}$ molecules in excited vibrational levels up to $v^{\prime}=6 .^{7}$ The $\mathrm{HF}$ molecules formed with the $\mathrm{SF}_{6}$ and $\mathrm{C}_{2} \mathrm{H}_{6}$ mixture are in excited vibrational levels up to $v^{\prime}=3$.

The output beam from the osclllator-preamplifier was expanded and propagated a distance of 31.5 meters to the $\lambda-3$ electron-beam-1nitiated intermediate amplifier.

The timing between the oscillator-preamplifier and the $\lambda-3$ intermediate amplifier was chosen to maximize the number of vibrational-rotational lines in the input spectrum for the duration of positive gain in the $\lambda-3$ intermediate amplifier. The duration of positive gain in the $\lambda-3$ can be obtained from the total output signal shown in Fig. 2. The time correlation between the $\lambda-3$ electron-beam current, total laser output and various p-branch transitions are shown in Fig. 2. The start of positive gain in the $\lambda-3$ system occurs about $35 \mathrm{nsec}$ after the start of the electron-beam current. As can be seen from the data, the vibrational-rotational lines from $P_{1}(7)$ up to $P_{3}(5)$ are lasing almost simultanenusly. Th1s information was used to deterimitie wheir an Input signal into $\lambda-3$ should occur. The time chosen for this input signal 


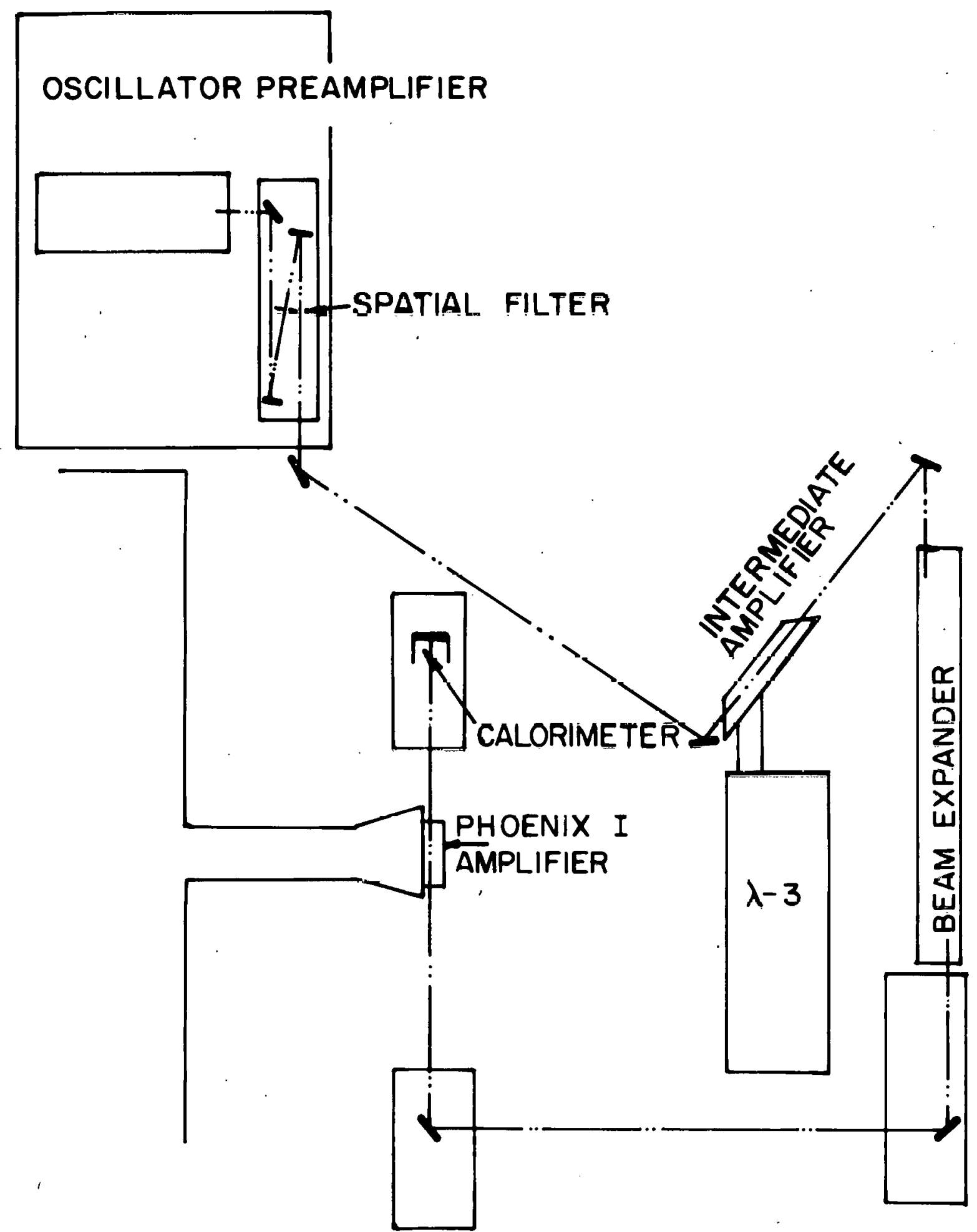

Fig. 1. Schematic representation of saturated amplifier experiment. 


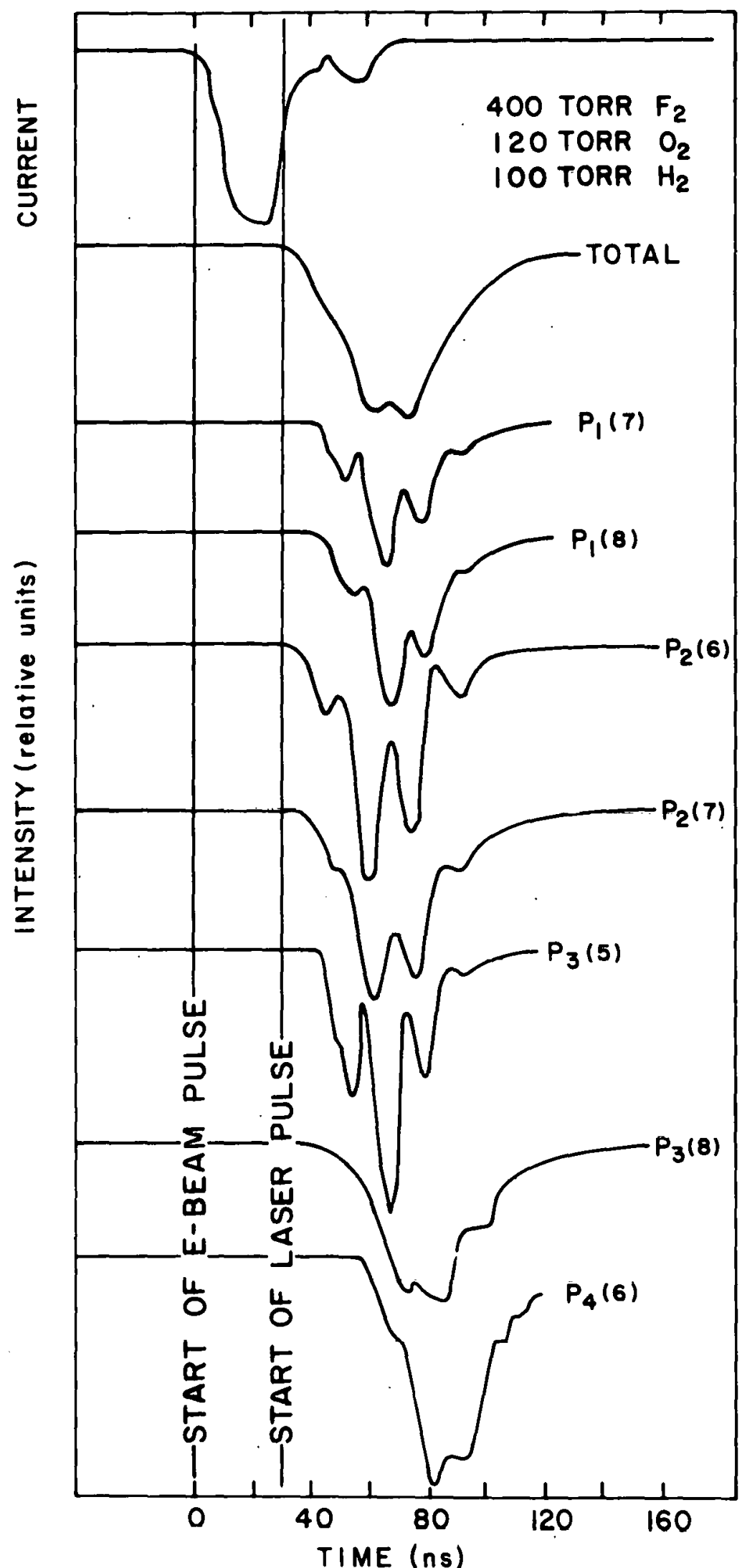

Fig. 2. Time correlation for the $\lambda-3$ intermediate amplifier between electron-beam current, total output and various $\mathrm{P}$-branch transitions for the $\lambda-3$ system configured as an oscillator. 
was about $30 \mathrm{nsec}$ after the start of the electron-beam current. The temporal behavior of the strongest vibrational-rotational lines from the oscillator-preamplifier has been measured and the principal features are shown in Fig. 3. The X's shown in Fig. 3 indicate the time of peak signal at each line. The time derived over which the intensity levels are greater than $10 \%$ and $5 \%$ of the maximum are also indicated in Fig. 3 .

Since the oscillator pulse width is much greater chan the positive gain duration of the $\lambda-3$ intermediate amplifier, we had to choose a time for insertion of the signal into $\lambda-3$ which contalned a maximum number of vibrational-rotational 11nes. The time chosen as indicated

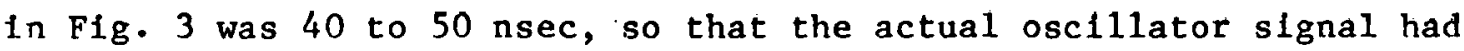
to be Inserted into the $\lambda-3$ preamplifier about 10 to $20 \mathrm{nsec}$ before the start of the electron-beam current.

After amplification in the $\lambda-3$ intermediate amplifier (operating with a total pressure of 620 Torr with a $F_{2}: 0_{2}: H_{2}$ mixture of $1 . \cup: \cup \cdot 3: U .25$ ), the pulse had a width (FWHM) of about $60 \mathrm{nsec}$ and an energy of about $25 \mathrm{~J}$. This optical beam was then expanded and propagated to the Phoenix I amplifler. In the case for which maximum energy was required at the Input to Phoenix I, the optical beam out of the $\lambda-3$ intermediate amplifier was propagated directly to the Phoenix I amplifier. For that case, to ensure that the optlcal beam filled the aperture of the Phoenix I amplifier, the beam expander at the output of the oscillator-preamplifier was adjusted so that the beam was silghtly diverging. The input intensity to the amplifier was varied by an attenuator utilizing front surface reflections from varlous combinations of small-angle wedges made of quartz, $\mathrm{CaF}_{2}$ and $\mathrm{ZnSe}$.

The input beam intensity profile was determined using an infrared-pyroelectric Vidicon camera equipped with an F/0.7 Ge 1ens. A NaC1 scatter plate was used 


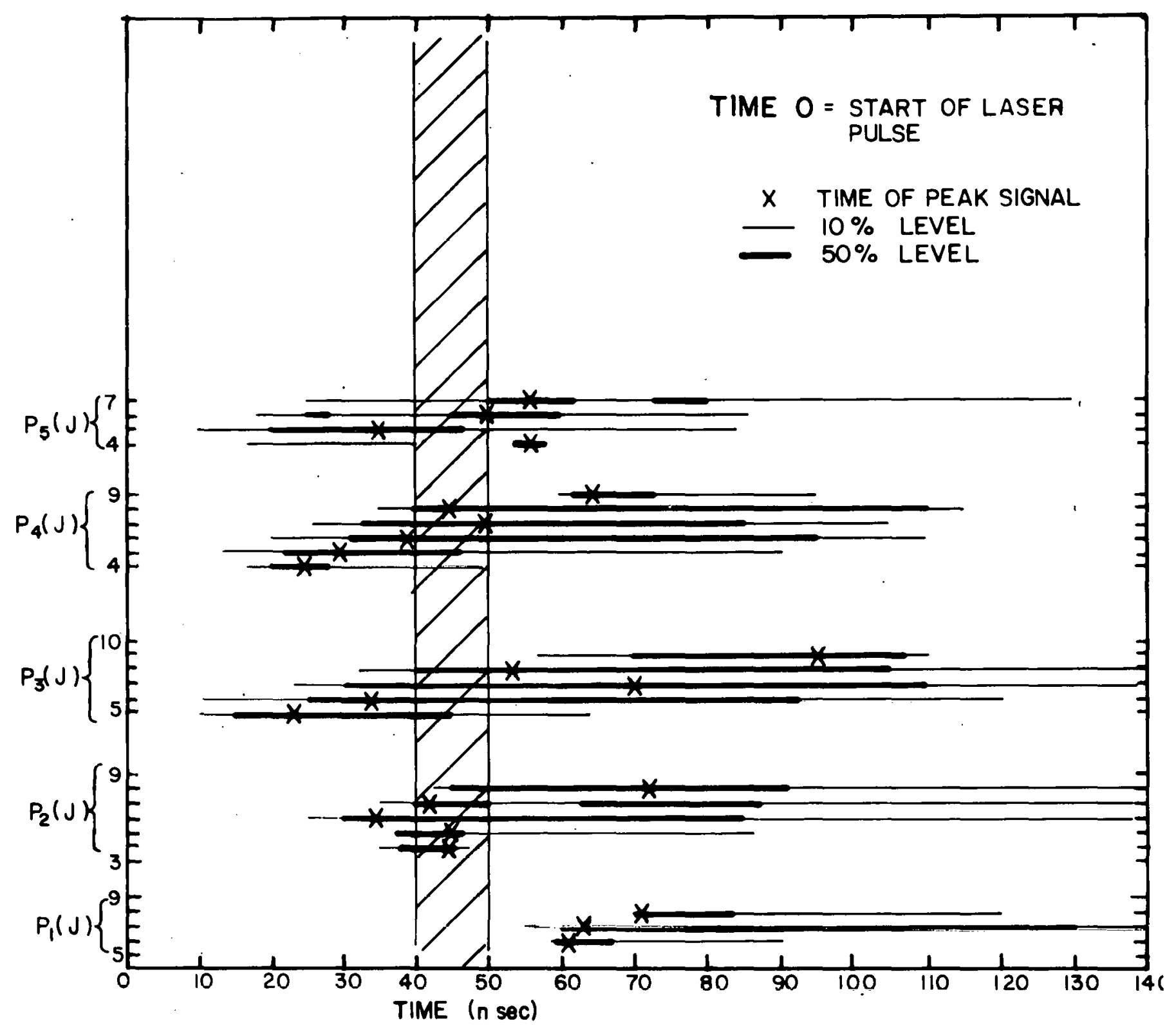

Fig. 3. Temporal behavior of the strongest vibrational-rotational lines from the oscillator-preamplifier. The time of the maximum periods over which the intensity levels are greater than $10 \%$ and $50 \%$ are indicated. The shaded area indicates the time chosen for the oscillator signal and the start of positive gain in the intermediate amplifier to overlap. 
to reduce the intensity incident on the camera. The input beam relative intensity profile is shown in Fig. 4. The ful1-width-half-maximum for the input beam was $5.8 \mathrm{~cm}$. The aperture of the Phoenix I cell was $7.54 \mathrm{~cm}$ so the edge intensity was about one-fourth of the center intensity.

The temporal behavior of the pulses from the oscillator-preamplifier, the $\lambda-3$ intermediate amplifier and the Phoenix I amplifier was measured with Au:Ge detectors cooled by 11quid nitrogen. The electron-beam currents for the $\lambda-3$ Intermediate amplifier and the Phoenix I amplifier were also monitored. All of the signals were time correlated to the center of the Phoenix I amplifier ce11. A set of time correlated data are shown in Fig. 5. These data were obtained with the oscillator-preamplifier operating with mixtures of $\mathrm{SF}_{6}-\mathrm{HI}$.

The input energy into the Phoenix I amplifler was measured using a quartz beam splitter and a 20-cm-diameter calorimeter. Th1s system was callbrated by comparison with another calorimeter which was placed directly in the input beam. This measurement was corrected for the transmission of the sapphire Input window of the Phoenix I amplifier.

The collimated output energy from the Phoenix I amplifier was measured with a 20-cm-diameter total-absorbing calorimeter. In order to separate the collimated output energy from radiation emitted at large angles by amplified spontaneous emision (ASE), the calorimeter used to measure the collimated output was apertured and was locáted 5.6 meters froin the cencer of the amplifier. The energy due to ASE in the forward and backward directions was measured using quartz beam splitters and $20-\mathrm{cm}$-diameter calorimeters. The collimated beam energy was eliminated from the forward ASE measurement by placing a mask in front of the calorimeter. This calorimeter then measured energy which was proportional to the energy in forward ASE. 


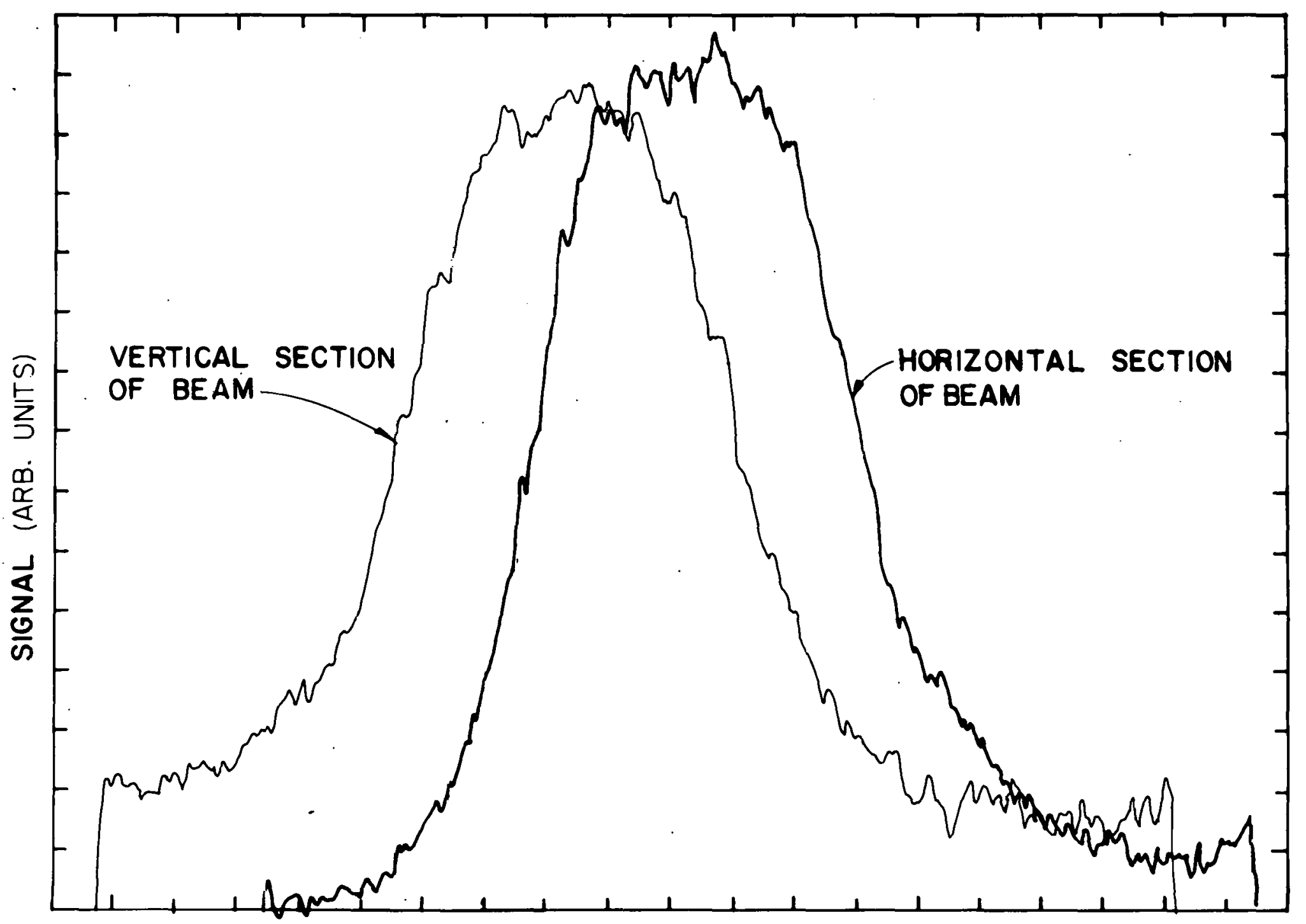

\section{CENTIMETERS}

Fig. 4. Re-ative intensity profile of input beam into Phoenix I amplifier. The vertical profile and.horizontal profile are indicated. The horizontal profile has been shifted so that both profiles can be distinguished. One marked division of the abscissa is equal to one centimeter. 


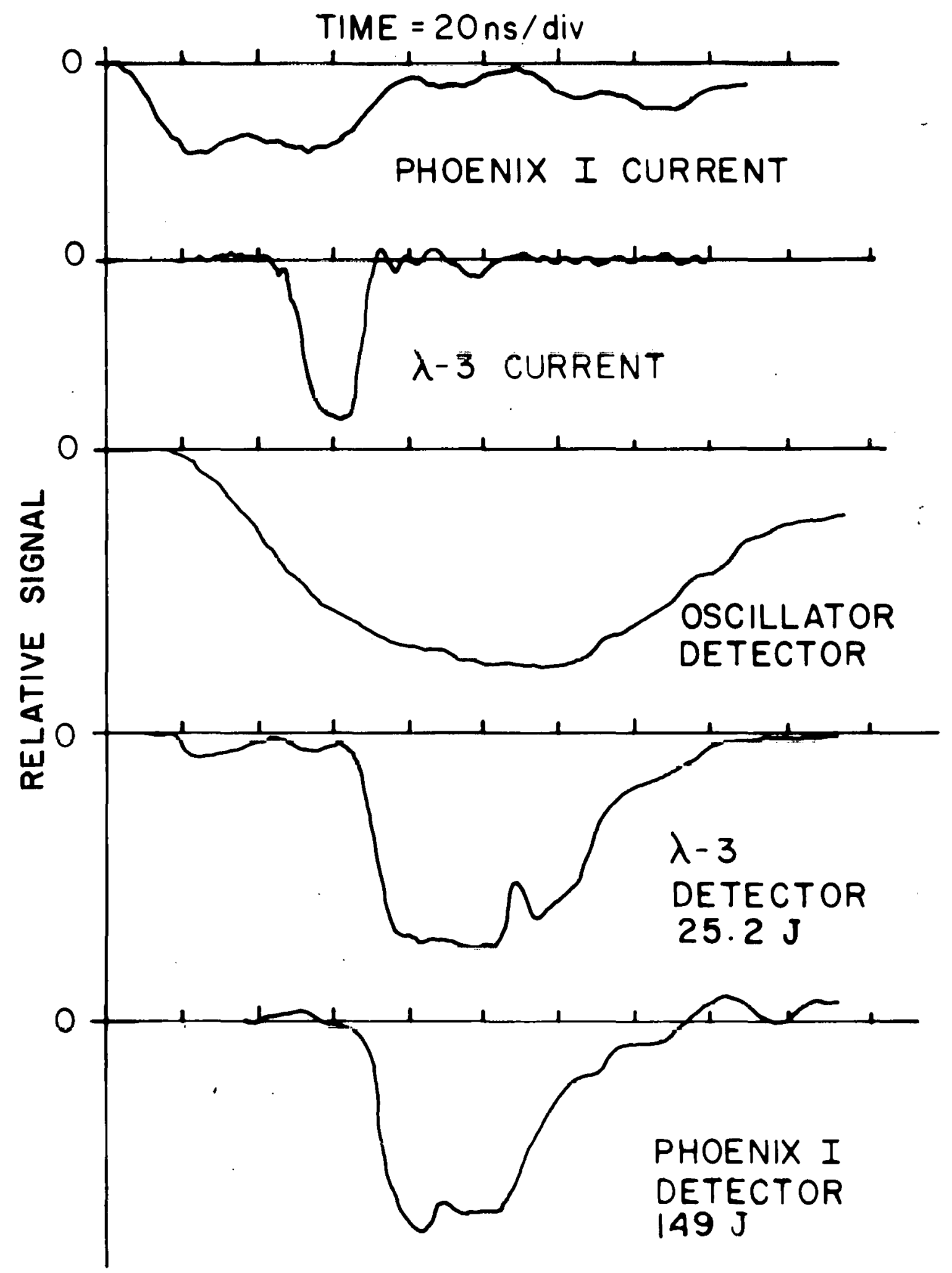

Fig. 5. Time correlated signals from the saturated amplifier experiment. The input and output energies are indicated. 
III. Results

The results of the energy extraction experiment are shown in Fig. 6 . The data points show the extracted energy from the Phoenix I chain. That 1s, $E_{\text {extracted }}=E_{\text {out }}-E_{1 n}$. The data points indicated by an $X$ are measurements made with the oscillator-preamplifier system operating on mixtures of $\mathrm{SF}_{6}-\mathrm{HI}$. The results of the previous experiment where the oscillator used mixtures of $\mathrm{H}_{2}$ and $\mathrm{F}_{2}$ are indicated by the open circles. The results from these two different experiments are the same within the estimated experimental error of $15 \%$. These results indicate that an oscillator-preamplifier system, operating on mixtures of $\mathrm{SF}_{6}-\mathrm{HI}$ is just as effective at extracting energy from an amplifier operating with $\mathrm{H}_{2}-\mathrm{F}_{2}$ as is an osc1llator operating with $\mathrm{H}_{2}-\mathrm{F}_{2}$ mixtures.

Extraction measurements were also made with the discharge-initiated oscillator and preamplifiers operating on mixtures of $\mathrm{SF}_{6}-\mathrm{C}_{2} \mathrm{H}_{6}$. The energy extracted for two different inputs are shown as triangles in Fig. 6. As shown in Fig. 6 , the results with $\mathrm{SF}_{6}-\mathrm{C}_{2} \mathrm{H}_{6}$ are only about $16 \%$ lower than the results obtained with $\mathrm{SF}_{6}-\mathrm{HI}$. This result is very useful because use of $\mathrm{SF}_{6}-\mathrm{C}_{2} \mathrm{H}_{6}$ avolds the increased difficulty in using $\mathrm{HI}$, which will photodissociate and thermally dissociate.

With no input into the Phoenix I amplifier, the calorimeter signals which are proportional to the ASE in the forward and backward directions were 4 and $7 \mathrm{~J}$, respectively. With an input of $1.6 \times 10^{6} \mathrm{~W} / \mathrm{cm}^{2}$, these signals were reduced to 1.5 and $2.3 \mathrm{~J}$, respectively. Increasing the Input Intensity above $1 \times 10^{6} \mathrm{~W} / \mathrm{cm}^{2}$ did not further reduce the amplified spontaneous emission. These results are similar to the first extraction experiment ${ }^{1}$ where a factor of two reduction was obtained for $10^{4} \mathrm{~W} / \mathrm{cm}^{2}$ but an increase in input intensity above that value did not further decrease the amplified spontaneous emission. The ASE results are not understood, but they may be influenced by parasitic 
ENER:SY-EXTRACTION-PHOENIX I $\triangle M P L I F I E R$

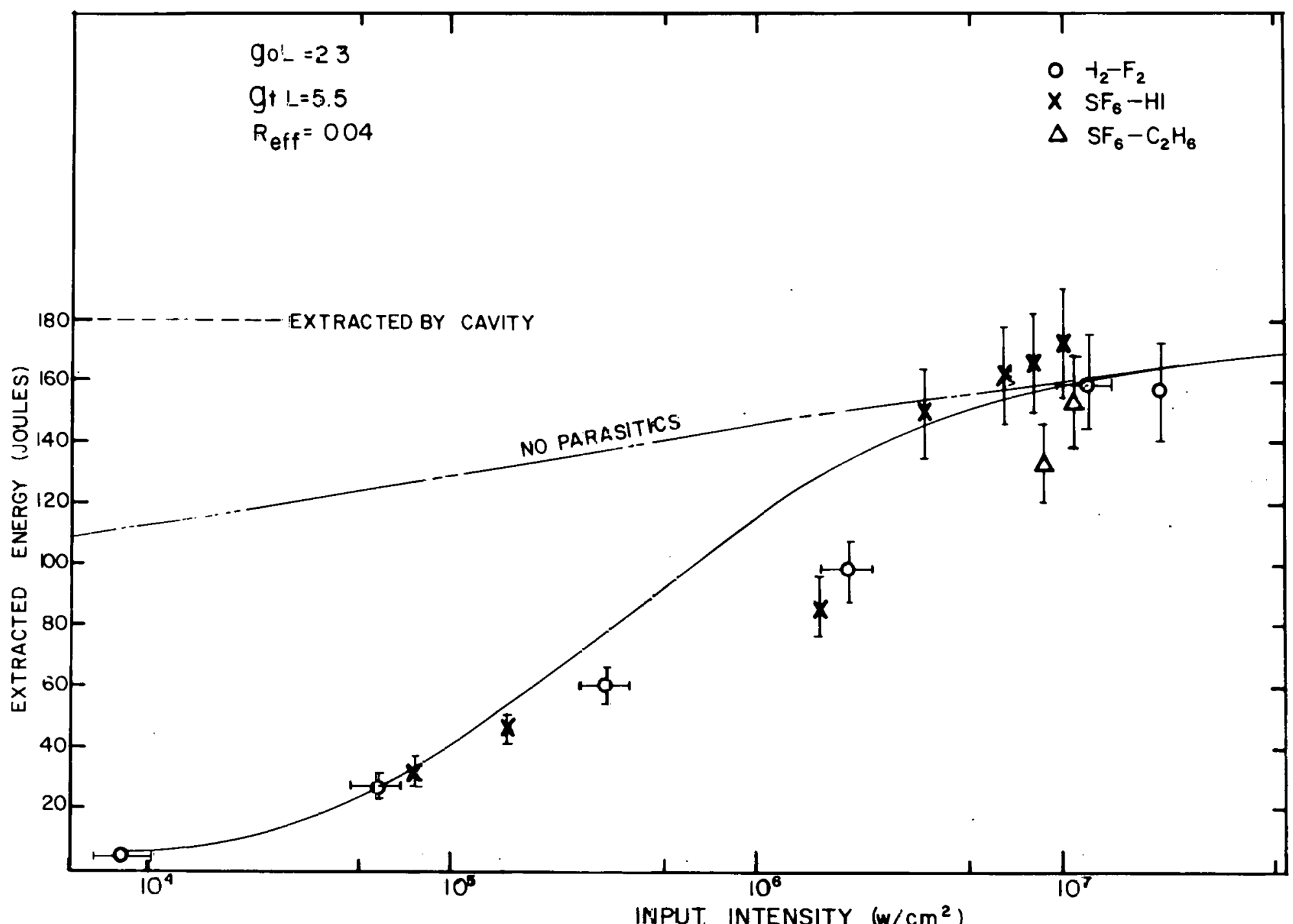

Fig. 6. Energy extractior from Proenix I as a function of input intensity: The error in measurement of the extracted energy is estinated to be $\pm 10 \%$ end the error in determining the impt intensity is estimated to be $\pm 20 \%$. The toial available extractec energy from the amplifier is indicated to be $180 \mathrm{~J}$. The solid curve is the result of a simple parcsitic model with the following parameters: $g_{0} L=23$, $\mathrm{g}_{t} \mathrm{~L}=5.5$, and $\mathrm{R}_{\mathrm{f}}=0.004$. The curve merked "No Parasitics" indicates the simple model predictions for energy extraztion when the reflection parameter is set equal to zerc. 
modes that are not dominated by the input radiation.

An energy-galn curve can be obtalned from the extraction data, where the energy gain has been defined as

$$
G_{E}=\frac{E^{\text {out }}}{E^{\text {in }}} \text {. }
$$

The energy-gain curve is shown in Fig. 7. The open circles are the gain data obtained from the first extraction experiment. The data marked $X$ in Fig. 7 show the energy gain obtalned from the experiment using an oscillator-preamplifier system operating with $\mathrm{SF}_{6}$-HI mixtures. For about $90 \%$ energy extraction from the Phoenix I amplifier, the energy gain is about 5 .

The HF laser is a complicated system which requires a rather sophisticated computer model to adequately describe the system. For quick estimates of performance of a system, it is advantageous to have some simple models. In an effort to develop a simple model, we first attempt to analyze the Phoenix I results using a simple model describing extraction in a quasi-steady-state amplifier that neglects amplified spontaneous emission and parasitic oscillations. The model considered Is two level, steady state with homogeneous broadening. 8 From this model the effective small-signal-gain-length product is given by

$$
\varepsilon_{0} I=\ln \left(\frac{I_{\text {ext }}}{I_{\text {in }}}+1\right) /\left(1-\frac{I_{\text {ext }}}{g_{0} L I_{s}}\right)
$$

where $I_{\text {ext }}$ is the extracted intensity, $I_{\text {in }}$ is the Input intensity and $I_{s}$ is the saturation intensity. From the published extraction data for Phoenix $I,^{1}$ the values of $g_{0} L$ at various input intensities have been 
ENERGY GAIN CURVE VS. INPUT ENERGY

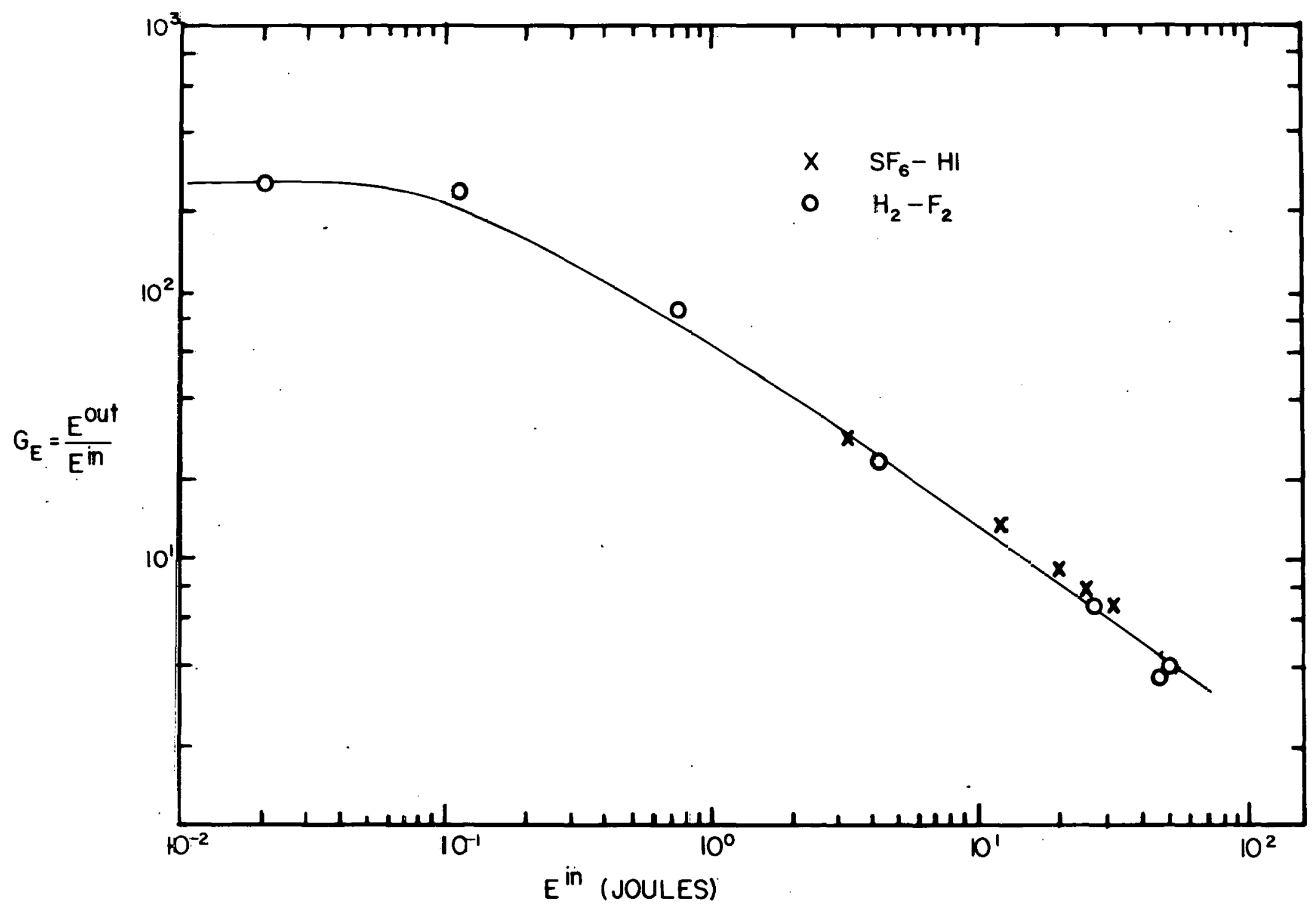

Fig. 7. Energy gain of Phoenix I as a function of imput enerby. 
calculated and are 118 ted in Table $I$.

Table I. Smal1-Signal-Gain-Length Product Obta1ned from Phoenix I Data Using a Two-Level Steady-State Amplifier Model

$\begin{array}{lrr}I_{1 \mathrm{n}}\left(\mathrm{W} / \mathrm{cm}^{2}\right) & \frac{E_{\text {ext }}(\mathrm{J})}{8.9 \times 10^{3}} & \frac{g_{0} L}{5.7} \\ 5.7 \times 10^{4} & 5.11 & 6.4 \\ 3.2 \times 10^{5} & 61.0 & 6.7 \\ 2.0 \times 10^{6} & 99.0 & 6.9 \\ 1.2 \times 10^{7} & 159.0 & 16.5 \\ 2.2 \times 10^{7} & 157.0 & 11.2\end{array}$

Results from the present experiment are 11sted in Table II.

Table II. Smal1-S1gnal-Galn-Length Product Obtalned from Present Phoenix I Extraction Data Using a

Two-Leve1 Steady-State Amplifier Model

$\begin{array}{lrr}I_{1 \mathrm{n}}\left(\mathrm{W} / \mathrm{cm}^{2}\right) & \frac{E_{\text {ext }}(\mathrm{J})}{g_{0} \mathrm{~L}} & \underline{g_{0}} \\ 1.6 \times 10^{6} & 86 & 5.9 \\ 3.5 \times 10^{6} & 150 & 16.6 \\ 6.3 \times 10^{6} & 162 & 23.5 \\ 8.0 \times 10^{6} & 166 & 27.0 \\ 1.1 \times 10^{7} & 170 & 30.0\end{array}$

From Table I and Table II 1 t is apparent that this simple amplifier model does not yleld a single value of $g_{0} L$ for this amplifier. The fact that this aimple amplifier model does not yield a single value of $g_{0}$ L may Indicate that parasitic oscillations are perturbing the operational characteristics of the laser amplifier.

The evaluation of the effect of parasitic oscillations on the operating characteristics of an HF laser amplifler requires that a second model be 
developed. The model we choose to consider is 1llustrated in Fig. 8 . Each window is assumed capable of reflecting light emerging from the amplifier back into the active medium. The reflected light is also assumed not to be coaxlal with the input beam.

For this particular case the transport equation is

$$
\frac{d I^{ \pm}}{d x}= \pm \frac{g_{0} I^{ \pm}}{I+\frac{I}{I_{s}}}
$$

where $I=I^{+}+I^{-}$. Th1s equation can be solved for the given boundary conditions and the solution is the following equation:

$$
g_{0} I=\ln G+\frac{I_{i}^{+}}{I_{s}}\left[\left(I-R_{0} G\right)(G-1)\right] \text {. }
$$

where $G=I^{+} / I_{i}^{+}$, and $R_{0}$ is the effective reflectance of the output window. This equation can be put into a more tractable form if the following identity relating extraction efficlency and $I_{i}^{+}$is used:

$$
\eta_{\text {ext }} \dot{=} \frac{I_{i}^{+}(G-1)\left(1-R_{i} R_{0} G^{2}\right)}{g_{0} I_{s}} \text {, }
$$

where $R_{i}$ is the effective reflectance of the input window and $\left(1-R_{1}\right)$ and $\left(I-R_{0}\right) \approx 1.0$. Combining the above two expressions in order to eliminate $I_{i}^{+}$, the extraction efficiency is given by

$$
\eta_{\text {cxt }}=\frac{1-R_{i} R_{0} G^{2}}{\left(1+R_{0} G\right)}\left[1-\frac{1}{g_{0} L} \ln G\right] \text {. }
$$

The required input intensity for this extraction efficiency at the given value of $G, g_{0} L, R_{1}$ and $R_{0}$ is given by the 1dentity 


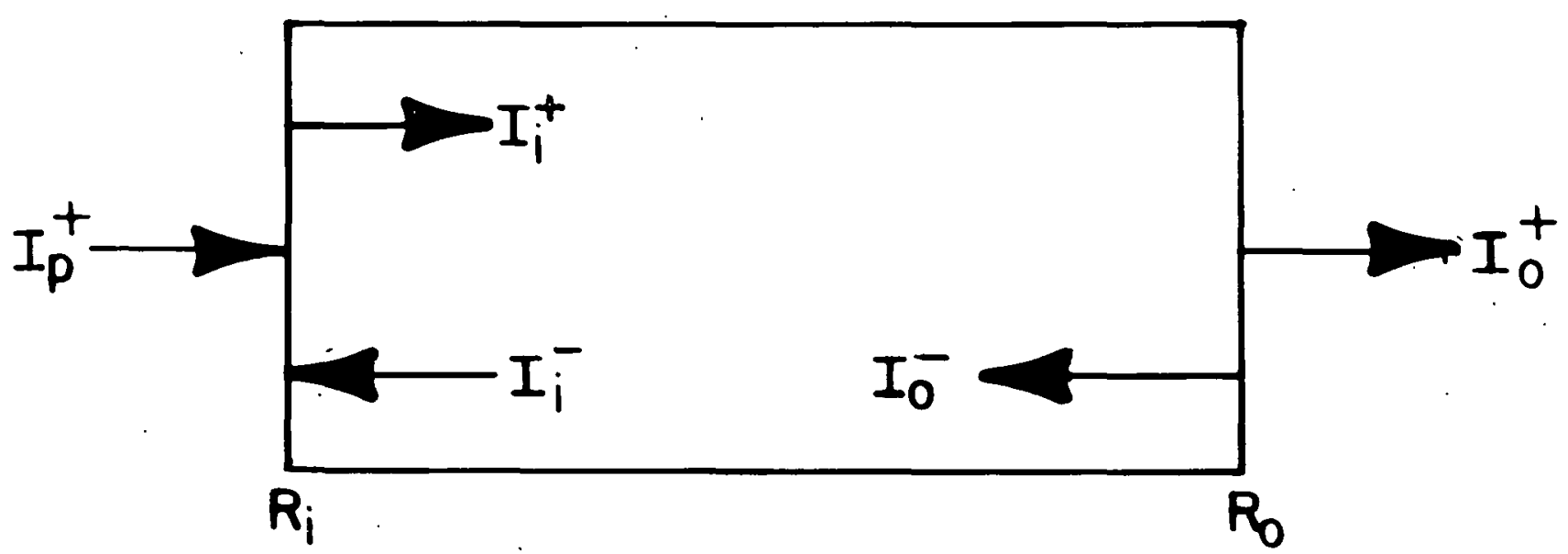

$$
\begin{aligned}
& I_{i}^{+}=I_{p}^{+}\left(1-R_{i}\right)+R_{i} I_{i}^{-} \\
& I_{i}^{-}=R_{0} G^{2} I_{i}^{+} \\
& I_{0}^{-}=R_{0} I_{i}^{+} G \\
& I_{0}^{+}=I_{i}^{+} G\left(1-R_{0}\right)
\end{aligned}
$$

Fig. 8. Schematic representation of steady-state parasitic model. $R_{\mathbf{i}_{+}}$and $R_{0}$ are the reflectivity of the input and output window, respectively. $I_{-}^{+}$is the input intensity into the amplifier and $I_{0}^{+}$is the amplifier output intensity. $I_{0}^{-}$ is the intensity reflected along the amplifier optical axis from the output window. $I_{i}$ is the amplified backward intensity on the input window and $I_{i}^{+}$ is the total intensity in the forward direction. 


$$
I_{p}^{+}=\frac{\eta_{\text {ext }} g_{o} L_{s}}{(G-I)}
$$

By varying $G$ from exp $g_{0} L$ to 1.0 in Eqs. (6) and (7), one can vary

$\eta_{\text {ext }}$ versus $I_{p}^{+}$for an amplifier which has parasitic oscillations. For the case of symmetric effective window reflectance, $R_{0}=R_{1}=R$, Eq. (6) becomes

$$
\eta_{\text {ext }}-(1-R G)\left[1-\frac{1}{R_{u} L} \ln G\right] \text {. }
$$

The value of effective window reflectance $R$ is obtalned from the relation

$$
g_{t} L=-\ln R
$$

where $g_{t} L$ is the parasitic controlled gain-length product, and for this case it can be obtained from the gain curve for smal1-signal input (see F1g. 7). The gain $G=e^{-\ell n R}$ is about 250 for smal1-signal input, and this leads to an effective window reflectance of 0.004 . Th1s is not the actual reflectance of the windows of the laser amplifier but is the fraction of the output intensity which is reflected in the direction of the optical axis either by scattering from the windows or reflections from the windows being redirected by the cell walls. The value of $\mathrm{g}_{0} \mathrm{~L}$ used in this calculation is taken to be approximately the average of values of the last two entries in Table II and the three entries in Table II. It was found that the shape of the predicted energy extracted curve is not very sensitive to the assumed value of $\mathrm{g}_{\mathrm{o}} \mathrm{L}$.

The results of the parasitics model are shown by the solid curve in 
Fig. 6. The simple model calculations are in reasonably good agreement with the experimental energy extraction data. Th1s agreement maybe fortuitous since there is some doubt about how well a simple steady state model represents a pulsed HF amplifler. The dashed curve In Fig. 6 marked "no parasitics" Indicates the predicted energy extraction as a function of input intensity obtalned from this model if no parasitic oscillations are permitted in the amplifier.

The Sandia comprehensive HF code was also used to predict the amplifier behavior with and without parasitics. The version of the comprehensive HF code in which parasitic osclilations are modeled has been described previously. 7 The parasitics are approximated by transverse oscillations between the laser walls. In reality, the parasitic modes are probably more complicated so that an effective wall reflectivity is appropriate. This value is determined by assuming that parasitics dominate at the lowest measured input intensity. There the amplifier gain is just $\exp \left\{-(L / \ell) \ell_{n R}\right\}$, where $l$ and $L$ are the amplifier width and length, respectively, and $R$ is the effective wall reflectivity. Matching this expression to the measured gain at the lowest input intensity determined R. Figure 9 shows the computed results for Phoenix $I$, using a value of $R=0.41$. Also shown are results computed with $R=0$ and the experimental results. The value of $R$ used in the comprehensive code is different than the value used in the simple model, because the two models consider different parasitic modes and, therefore, use reflectivities characteristics of different surfaces and geometries. The smooth transition between poor extraction at low input and good extraction at high power is correctly predicted. These results from the simple model and the comprehenstve HF code lend credence to the assumption that energy extraction in the Phuentx I amplifier is strongly influenced by parasitic oscillations. 


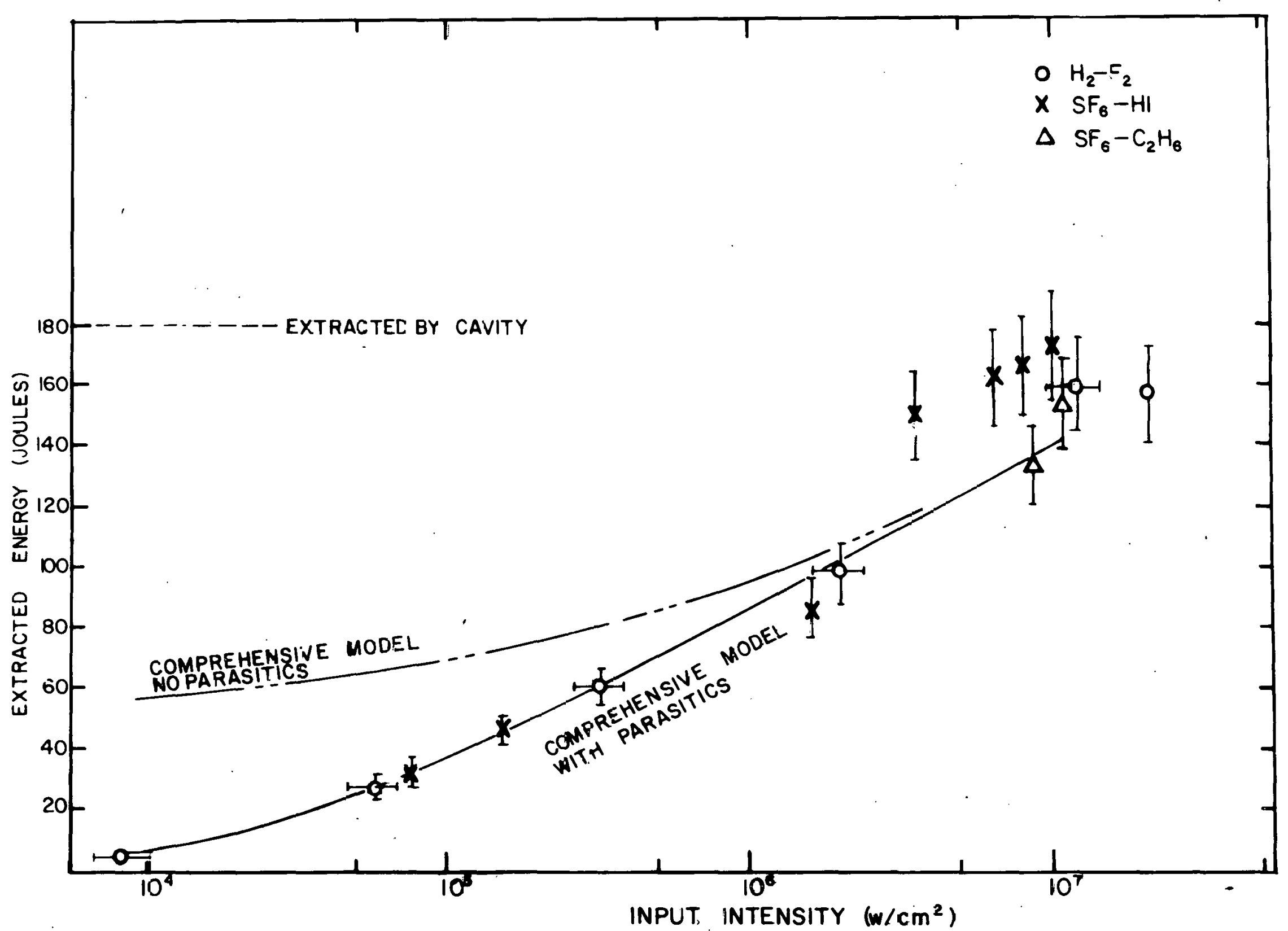

Fig. 9. Extracted energy as a function of imput intensity for Phoenix I. The discrete points are measured velues; the dashed and solid curves are calculations using the comprehensive code. The precictions are based on an approximate accounting for parasitic oscillaticns. 
Time integrated spectral data were acquired from the osclilator-preamplifier system, the $\lambda-3$ intermediate amplifier when driven by the oscillator, and the Phoenix I amplifier when driven by the complete chaln. These results are 11sted In Table III. Spectral data are shown for the oscillator-preamplifier system when operating with. mixtures of both $\mathrm{SF}_{6}-\mathrm{HI}$ and $\mathrm{SF}_{6}-\mathrm{C}_{2} \mathrm{H}_{6}$. Spectral data from the first extraction experiment, In which an $\mathrm{H}_{2}-\mathrm{F}_{2}$ fueled oscillator was used, are also listed. No relative intensitles are given but a visual Inspection of the spectra Indicates that most of the energy extracted from the Phoenix I system was contalned in the vibrational-rotational 1ines $P_{1}(7)$ up to $\mathrm{P}_{4}(6)$ when $\mathrm{SF}_{6}-\mathrm{HI}$ was used in the oscililator. This observation is confirmed by the $\mathrm{SF}_{6}-\mathrm{C}_{2} \mathrm{H}_{6}$ data where only vibrational-rotational Iines with $y^{\prime} \leq 3$ are extracted, yet the energy extracted from the amplifier is almost the same as that obtained with $\mathrm{SF}_{6}-\mathrm{HI}$. These data show that most of the energy extracted from an electron-beam-initiated HF amplifier operating with mixtures of $\mathrm{H}_{2}$ and $\mathrm{F}_{2}$ are contained within vibrational levels $P_{1}(7)-P_{4}(6)$, and that $85 \%$ of the energy can be extracted with an imput spectrum orfginating from the first three excited vibrational levels.

A lateral shearing interferometer ${ }^{3}$ was used to determine the change In the radius of curvature of optical beam produced by the Phoenix I amplifier. Interferograms were obtained at the input of the Phoenix I amplifier and at the output of the Phoenix I amplifier. The Input Interferogram was taken $8.33 \mathrm{~m}$ in front of the Phoenlx I Input window. The output Interferogram was located $11.6 \mathrm{~m}$ behind the location of the Input interferogram. A reproduction of the output interferogram is shown In Fig. 10. From the tilt of the interference lines with respect to the cursor wire, the radius of curvature of the wavefront was determined to he $67.8 \mathrm{~m}$ at the 1 input and $88.5 \mathrm{~m}$ at the output. For a spherical wave 
Table III. Spectral Comparison with Various Gas Mixtures

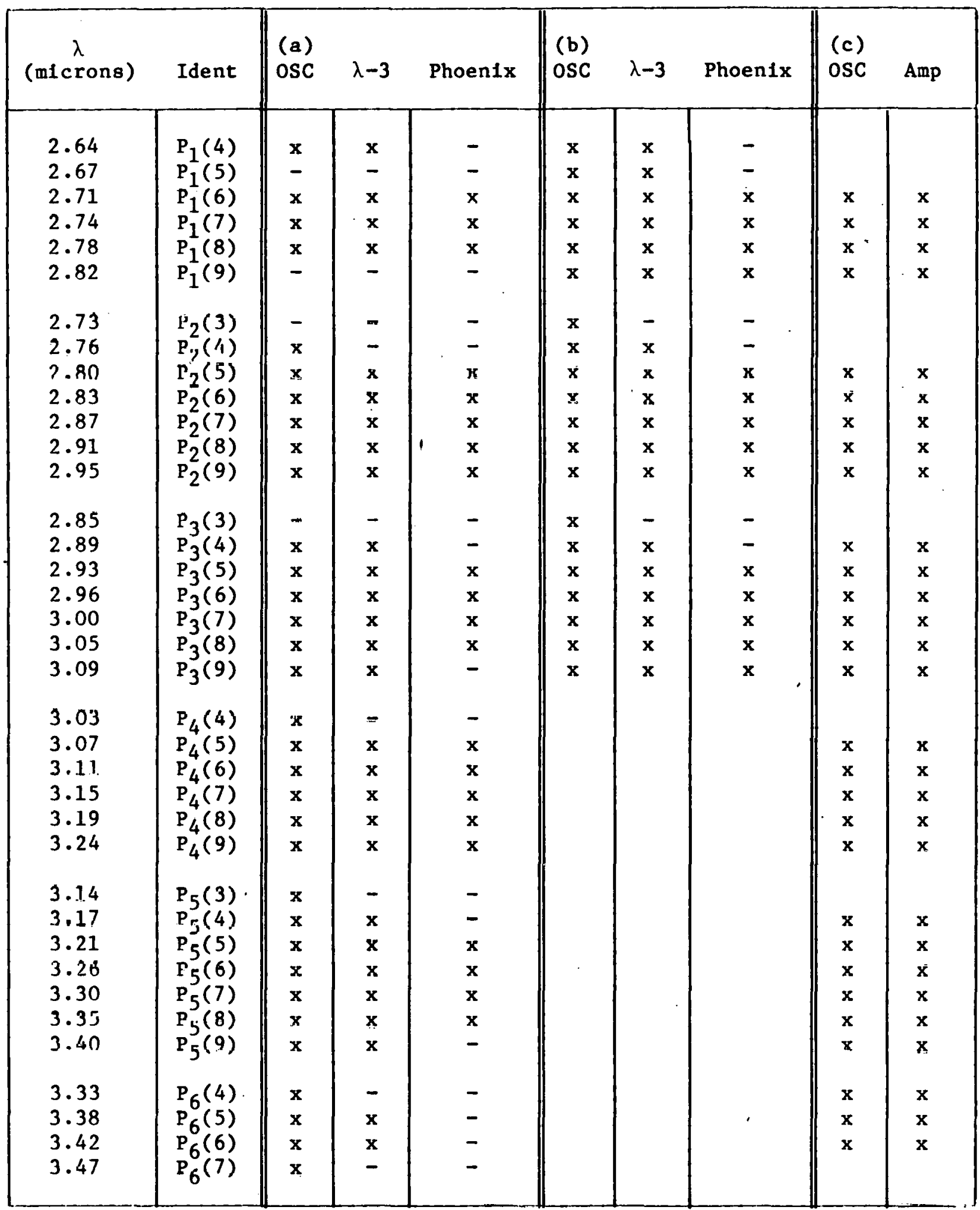

(a) The oscillator-preamplifier was operated with $\mathrm{SF}_{6}-\mathrm{HI}$.

(b) The oscillator-preamplifier was operated with $\mathrm{SF}_{6}-\mathrm{C}_{2} \mathrm{H}_{6}$.

(c) These results are from the first extraction experiment and the oscillator was operated with $\mathrm{H}_{2}-\mathrm{F}_{2}$. There are some very weak 11 nes out of the amplifier which have been identifled but are not listed. These lines are the following: $P_{1}(14-18), P_{1}(21), P_{2}(4), P_{4}(4), P_{5}(10), P_{6}(7)$. 


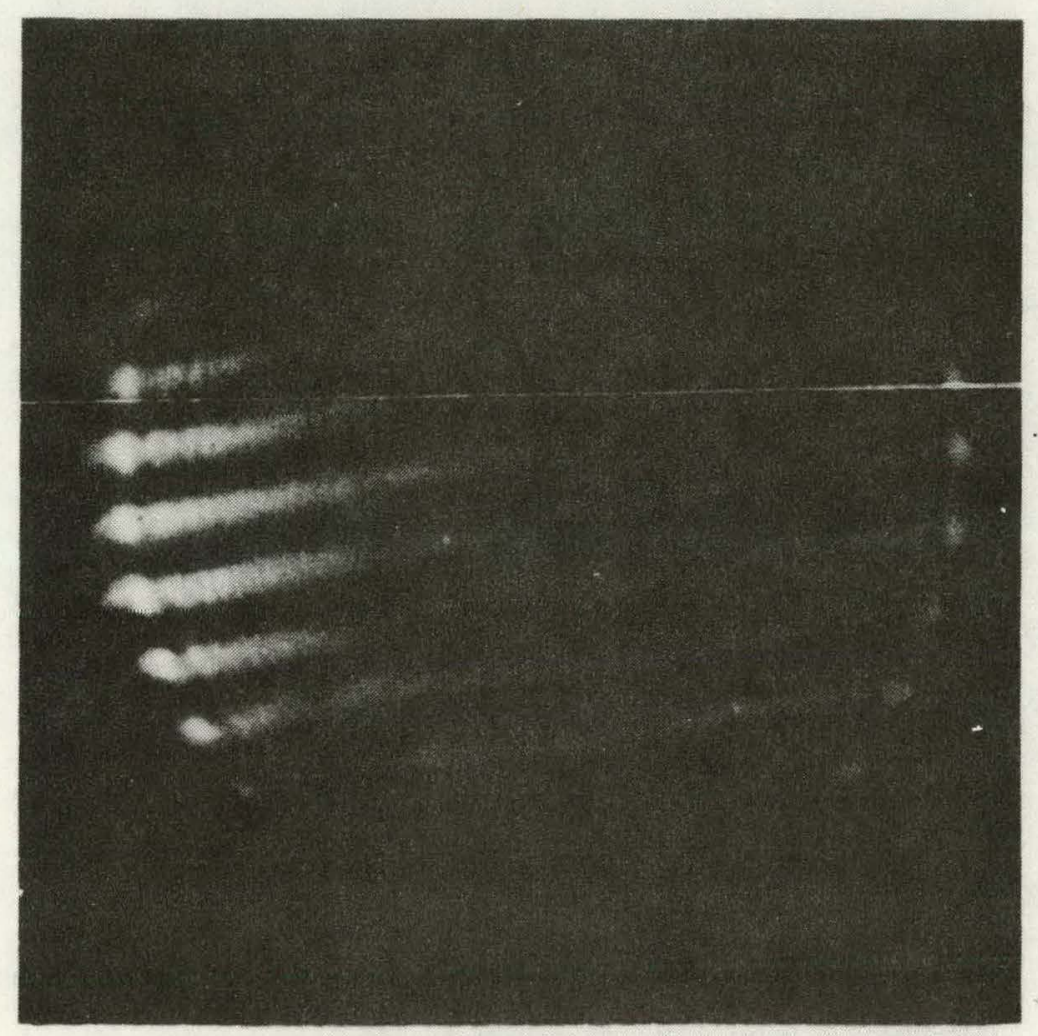

Fig. 10. Phoenix I shear plate interferogram. 
the radius of curvature of the wavefront should change by $11.6 \mathrm{~m}$ in going between between the two interferometer locations. The measured radius of curvature of the output beam Indicates that the amplifier is alter the radius of curvature of the wavefront.

IV. Summary

The results presented here show that energy extraction from the Phocnix I amplifier is as efficient when the input signal is generated from an oscillator operating with mixtures of $\mathrm{SF}_{6}-\mathrm{HI}$ as when the oscillator operates with $\mathrm{H}_{2}$ and $\mathrm{F}_{2}$. For an input intensity of $10^{7} \mathrm{~W} / \mathrm{cm}^{2}$, about $170 \mathrm{~J}$ were extracted from the amplifier. This corresponds to an extraction efficiency of $94 \%$. It was also shown that it is possible to develop a simple parasitic model which gives an adequate fit to the experimental extraction data. At low input intensity, models that were constructed indicate that parasitic oscillations strongly affect energy extraction.

Time-integrated spectral results showed that most of the energy extracted from the amplifier was contained in vibrational-rotational lines from $P_{1}(7)$ up to $P_{4}(6)$. This result suggests that if the oscillator-preamplifier were operated with $\mathrm{SF}_{6}-\mathrm{C}_{2} \mathrm{H}_{6}$ mixtures, then the energy extraction should be somewhat less than when operated with $\mathrm{SF}_{6}-\mathrm{HI}$. Two extraction measurements made with the oscillator-preamplifier operating with $\mathrm{SF}_{6}-\mathrm{C}_{2} \mathrm{H}_{6}$ mixtures were ahout $16 \%$ lower than the results obtained with $\mathrm{SF}_{6}-\mathrm{HI}$.

An attempt was made to determine if $\Lambda \mathrm{SE}$ was reduced as the input intensity was increased. As in the previous energy extraction experiments, the ASE was reduced by a factor of 2 or 3 at low input intensities $\left(1 \times 10^{6} \mathrm{~W} / \mathrm{cm}^{2}\right)$ but was not further reduced as the input intensity was increased. The beam wavefront curvature before and after amplification was determined with a lateral shearing interferometer. The wavefront curvature was altered in passing through the Phoenix I amplifier. 


\section{REFERENCES}

1. J. M. Hoffman, E. L. Patterson, and R. A. Gerber, J. App. Phys. $\underline{50}$ (6), 3861 (1979).

2. E. L. Patterson, G. N. Hays, F. K. Truby, and R. A. Gerber, J. Appl. Phys. 50 (4), 2643 (1979).

3. M. E. Riley and M. A. Gusinow, App1. Opt. 16, 2573 (1977).

4. G. P. Arnold and R. G. Wenze1, IEEE J. Quantum Electron. QE-9, 491 (1973).

5. R. A. Klein, Sandia Nationa1 Laboratorles Report SAND79-1659, 1979, unpublished.

6. E. L. Patterson, "Phoenix I: A Transverse Electron-Beam-Initiated HF Laser Amplifier," Presented at the International Conference of Laser 19, Orlando, FL, December 17-21, 1979.

7. N. R. Greiner, IEEE J. Quantum Electron. QE-11, 1844 (1975);

N. R. Greiner, IEEE J. Quantum Electron. QE-8, 872 (1972); and

S. W. Mayer, D. Taylor, and M. A. Kwok, Appl. Phys. Lett. 23, 434 (1973).

8. J. B. Moreno, G. A. Fisk, and J. M. Hoffman, J. Appl. Phys. 48, 238 (1977).

9. Laser Fusion Research Progress Report, July-December 1976, SAND77-1057, Sandia National Laboratories, Albuquerque, NM, May 1977. 
UNLIMITED RELEASE

Distribution:

US DOE/NS

Washinton, DC 20545

Attn: 0 . Lewis

Los Alamos Scientific Laboratory

P. 0. Box 1663

Los Alamos, NM 87544

Attn: C. Fenstermacher

University of California

Lawrence Livermore National Laboratory

P. U. Bux 808

Livermore, CA 94550

Attn: L. D. Pleasance

R. A. Haas

E. V. George

Mathematical Sciences Northwest, Inc.

P. O. Box 1887

Bellevue, WA 98009

Attn: J. J. Ewing

W. J. Schafer Associates, Inc.

1901 North Ft. Myer Drive

Sulte 803

Arlington, VA 22209

Attn: E. Gerry

TRW

1 Space Park

Redondo Beach, CA 90278

Attn: R. Aprahamian

Advanced Research Projects Agency

1400 Wilson Boulevard

Arlington, VA 22209

Attn: J. Mangano

AVCO Everett Research, Inc.

Everett, MA 02149

Attn: J. Daugherty

US Air Force

A1.r Force Weapons Laboratory

Kirtland AFB, NM 87117

Attn: F. J. Ortwerth, ALC

Maj. B. D. Crane

Capt. S. R. Czyzak
US Naval Research Laboratory

Washington, DC 20390

Attn: S. K. Searles

Maxwell Labs

9244 Balboa Avenue

San Diego, CA 92123

Attn: A. Kolb

Physics International

2/00 Merced Street

San Loandro, riA 94577

Attn: J. Martinez

Osaka Untversity

Institute of Laser Engineering

Osaka 565, Japan

Attn: C. Yamanaka

Keio University

Department of Electrical

Englneering

3-14-1 H1yosh1, Kohoku-Ku

Yokohama 223, Japan

Attn: Tomoo Fujloka

Minoru Obara

4000 A. Narath

4200 G. Yonas

4210

4211

4212

4212

4212

4212

4212

4214

4216

4218

4220

4230

4240

4250

8266

3141

3151

J. B. Gerardo (5)

E. J. McGulre

R. A. Gerber

J. M. Hoffman (5)

E. L. Pattersún (5)

G. C. Tisone (5)

J. B. Moreno (5)

E. D. Jones

A. W. Johnson

J. K. Rlce

M. Cowan

J. E. Powel1

G. W. Kuswa

T. H. Mart1n

E. A. Aás

T. L. Werner (5)

W. L. Garner (3)

(for DOE/TIC)

3154-3 R. P. Campbe11 (25) 


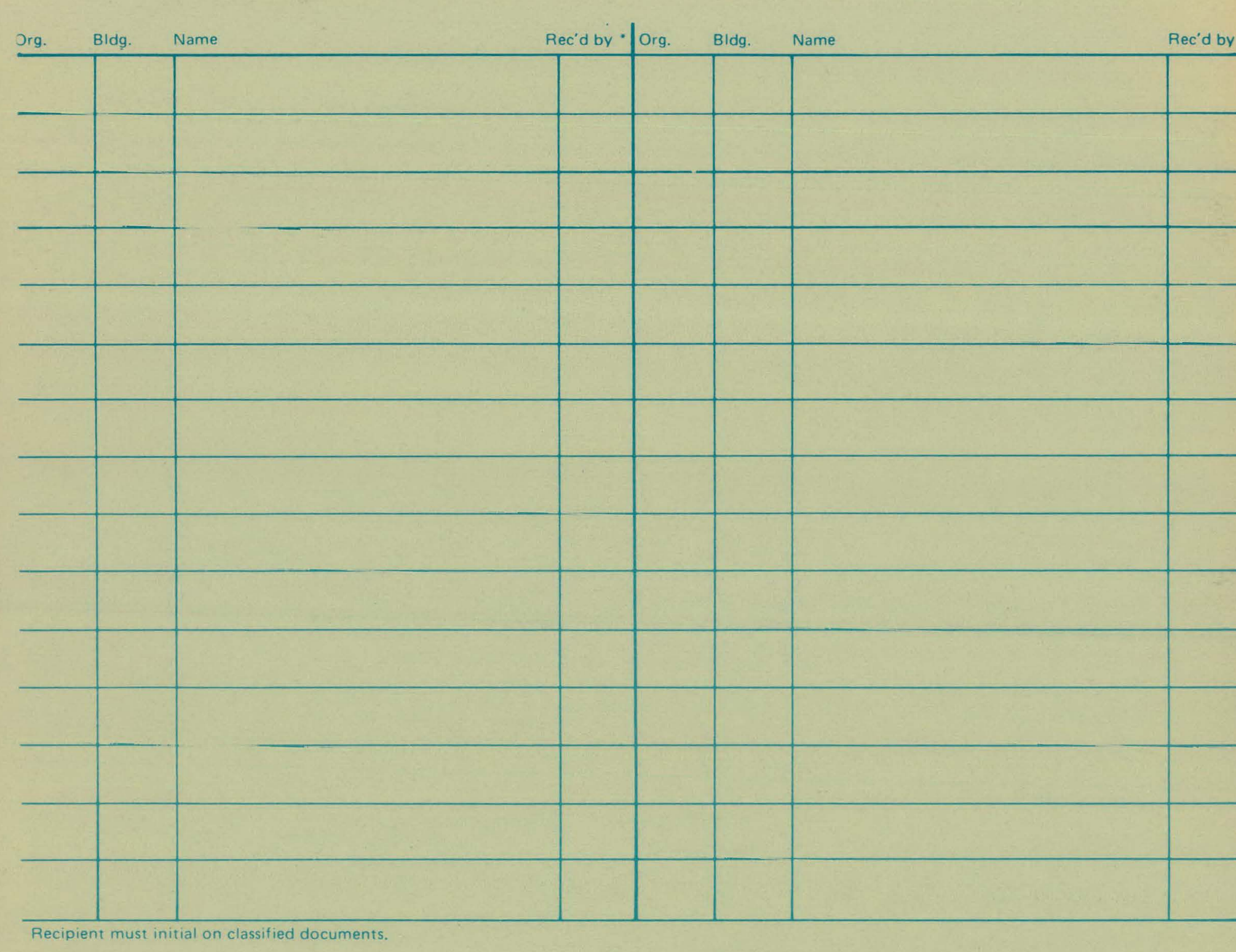

